\title{
THERMAL PERFORMANCE OF WALL AND ROOF ELEMENTS IN RESIDENTIAL BUILDINGS
}

\author{
Natarajan E. ${ }^{1}$, Vijayalakshmi M. M. ${ }^{2}$, Shanmugasundaram V ${ }^{3}$. \\ ${ }^{1}$ Institute for Energy Studies, Anna University, Chennai \\ ${ }^{2}$ Department of Civil Engineering, Sathyabama University, Chennai \\ ${ }^{3}$ Department of Civil Engineering, Anna University, Chennai \\ Email: 1enat@annauniv.edu
}

\begin{abstract}
Energy is a vital necessity for the growth of a modern technology. Energy consumption steadily increases due to increased population, improved modern life and increased industrialization. Residential buildings consume considerable amount of energy in any country. The thermal design of the building envelope is gaining wide importance to control the energy consumed by the buildings for maintaining comfortable indoor conditions. Proper design of envelop is found to decrease the unwanted heat gain from 5 to $50 \%$, depending upon extent of envelop design and selection of appropriate materials.
\end{abstract}

Key words: Thermal Performance, Wall, Roof, Buildings, heat gain, U-Value, Solar Design

\section{INTRODUCTION}

Buildings play a major role in the day-to-day and overall life of human beings. The living condition inside a building is determined by the climatic conditions and the elements of the building. Efficient use of energy will pave way for sustainable development, as it results in better utilization of energy and less pollution. It leads to reduced amount of thermal energy needed to produce electrical energy and subsequently results in saving of money. It also helps the environment in the way of reduced pollutants emitted into the atmosphere.

Energy savings in a residential building can be achieved by appropriate energy-efficient design of a building. Traditional solutions of providing thermal comfort by extensive plantation-oriented landscaping and heavy mass buildings are no longer valid because of land costs and shortage of building materials in developing countries. However, traditional respect for environment coupled with newer scientific developments in building materials, structural design, and decentralised utilization of energy-efficient appliances can be used to identify new and more sustainable solutions.

Residential buildings are usually designed to provide comfortable shelter for the occupants with minimal variation in indoor conditions and minimal requirements for space conditioning by external means. The performance of buildings is quantified by important parameters like thermal performance, spatial performance, visual performance, acoustic performance, indoor air quality and building integrity. The actual range of values for each parameter depends on the type of building, kind of occupants, type of activity and ambient conditions.

\section{A. HEATTRANSFER MECHANISM}

The arrangements of different layers in a conventional wall are shown in Figure 1. The thermal resistance (R-value) of a layer (per unit area) of building element is the ratio of its thickness to its thermal conductivity. Of all common materials, air has the lowest thermal conductivity and hence it is the best insulator, as long as it is kept still. If the convection current develops in the trapped air, the insulating effect is destroyed. Thus, the best insulating materials are manufactured with trapped air bubbles. Foams and porous materials having closed cells are the best insulators.

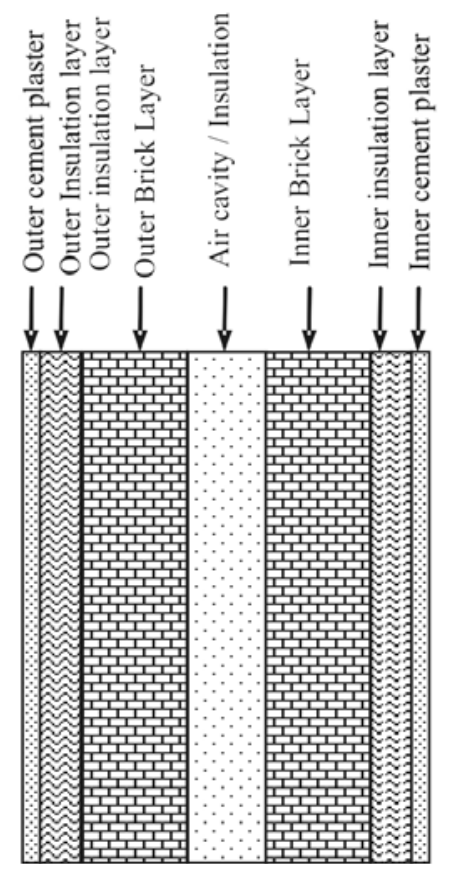

Fig. 1. Arrangements of Different Layers in A Conventional Wall 
For a multi-layer building wall (or roof), the total R-value will be the sum of the resistances of individual layers $(R 1, R 2, R 3, \ldots)$ plus the inside and outside surface film resistances (Rfi, Rfo) plus the cavity resistance (Rcv). A resistance network is made for each compound wall (made of number of layers) and the total resistance is calculated based on the concepts similar to electrical resistance network. The overall heat transfer coefficient of the compound wall $(U)$ is taken as the reciprocal of the total thermal resistance.

The roof of a building consists of inner layer of cement plaster, reinforced concrete, layer of insulation (if any), weather proof layer and a layer of tiles on the outer layer to reflect the incoming solar radiation.

The false ceiling (insulating) layer may be provided to further reduce the heat transfer, as shown in Figure 2. The roof of a building consists of inner layer of cement plaster, reinforced concrete, layer of insulation (if any), weather proof layer and a layer of tiles on the outer layer to reflect the incoming solar radiation. The false ceiling (insulating) layer may be provided to further reduce the heat transfer, as shown in Figure 2.

\section{B. THERMAL TIME LAG}

The internal surface temperature of the wall chang es with time due to change in solar radiation on wall,outer air temperature, thermo-physical properties of wall material and the inner environmental conditions. The solar radiation and outer air temperature causes a continuous change in the temperature distribution through the wall. The variation of surface temperature in a typical case is shown in the Figure 3.
Thermal time lag is the time delay between the occurrence of maximum temperature at the inside and outside of wall surface during periodic flow of heat (Asan and Sancaktar, 1998). It is expressed in hours. It increases with increase in wall thermal capacity.

\section{THERMAL PERFORMANCE INDEX}

The thermal performance index (TPI) of a non-airconditioned building (BIS 1978, 1995) is given by TPI = (Tis -30$)^{*} 100 / 8$, where Tis is the peak inside surface temperature. In this equation, a temperature drop $8^{\circ} \mathrm{C}$ over a base temperature of $30^{\circ} \mathrm{C}$ is taken as a reference.

\section{METHODOLOGY}

The solar energy incidence on the building surfaces depends on the location and the heat penetrating into the living space depends on the physical and thermal properties of the material of the building element.

The analysis of the thermal performance mainly depend on the calculation of solar energy incidence and judicious use of thermo=physical properties of the opaque elements of residential building.

The adaptive approach on thermal comfort (Humpherys 1978, Nicole and Humpherys 2002) emphasizes on adaptive principle, whichstates that if a change occurs such as to produce discomfort, people react in ways, which tend to restore their comfort.

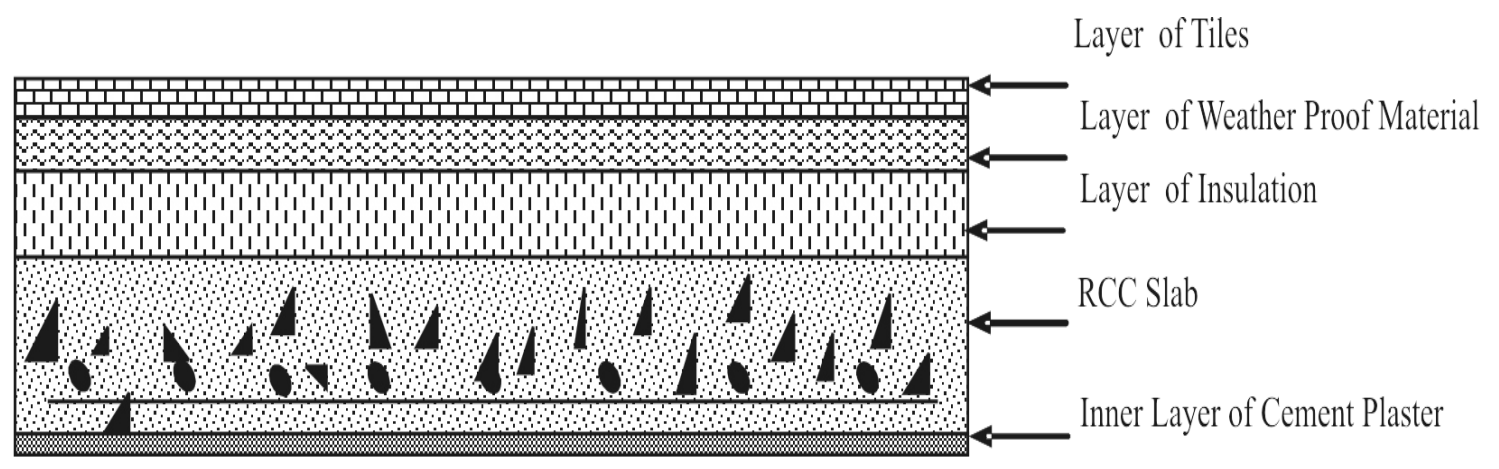

Fig. 2. Arrangements of Different Layers in a General Roof 


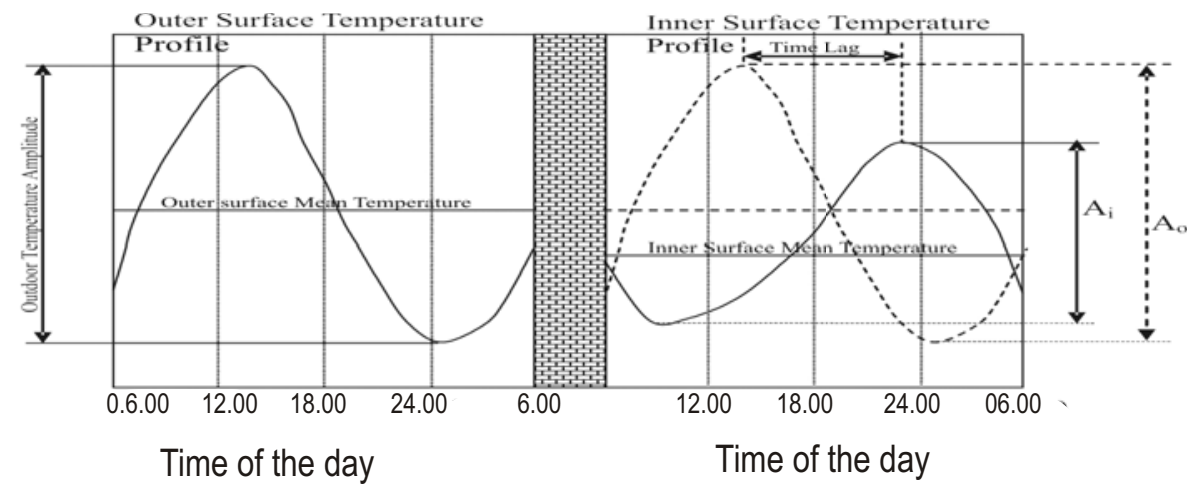

Fig. 3. Indoor and Atmospheric Temperature Variations

The options available for people to react depend on their situation. Those who have more opportunities to adapt themselves to the environment or the environments to their own requirements will be less likely to suffer discomfort. The prime variable in adaptive control is the climate, which has strong influence on the cultural and thermal attitudes of any group of people and on the thermal design of the buildings in which they inhabit. Although the basic relationship of the human beings with the environment remains the same, there are number of ways in which the people are influenced by the climate.

For instance, the climate decides various options available for the people to respond themselves to the indoor climate. The second important variable in determining the thermal comfort is the thermal design of the building.
The third variable is the time of the year, according to which the indoor climate changes in free-running buildings (buildings with free open air ventilation).

The comfort temperature (Tc) in free running buildings is found to be a strong function of the outdoor monthly mean air temperature (Toa), according to $\mathrm{Tc}=$ $13.5+0.54$ Toa and it is plotted in the Figure 4 .

Thee methodology followed for the studies on thermal performance of opaque elements of residential buildings is outlined (Koenigsberger, 2000) in the flowchart shown in Figure 5. A simplified methodology for calculating total solar radiation on the building surface is outlined in Figure 6.

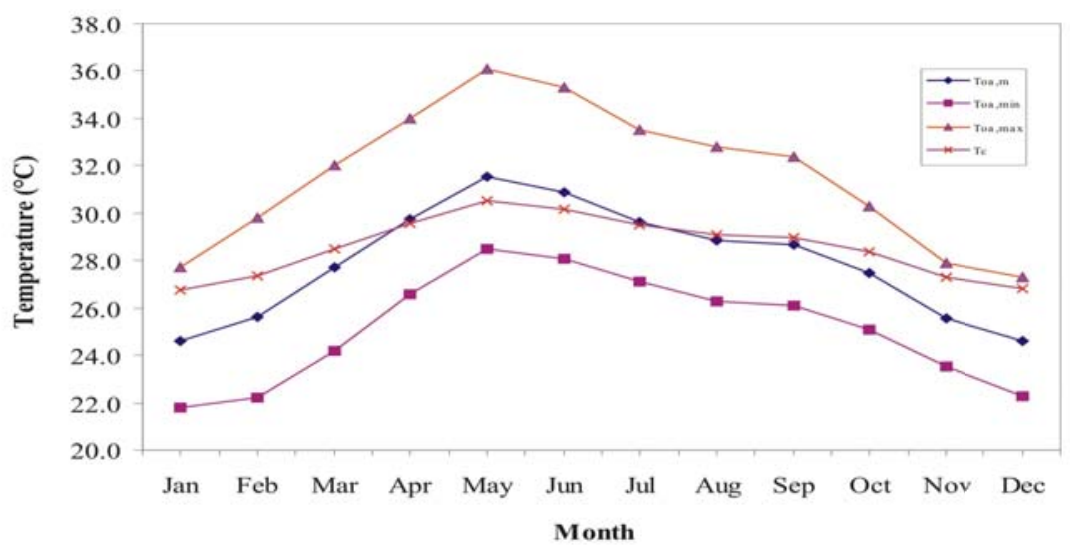

Fig. 4. Mean, Minimum, Maximum Air Temperatures and Adaptive Comfort Temperature 


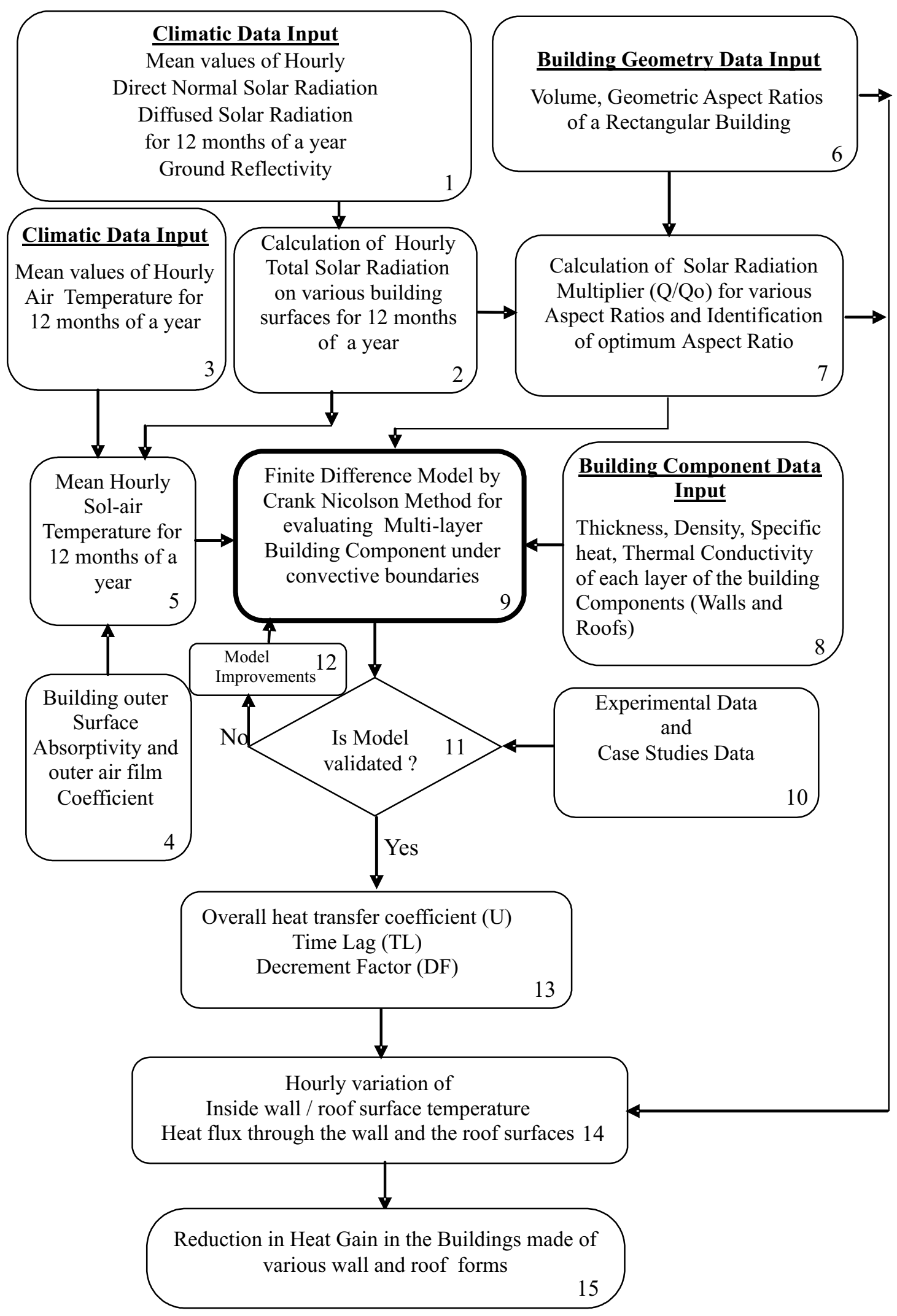

Fig. 5. Outline of the Methodology 


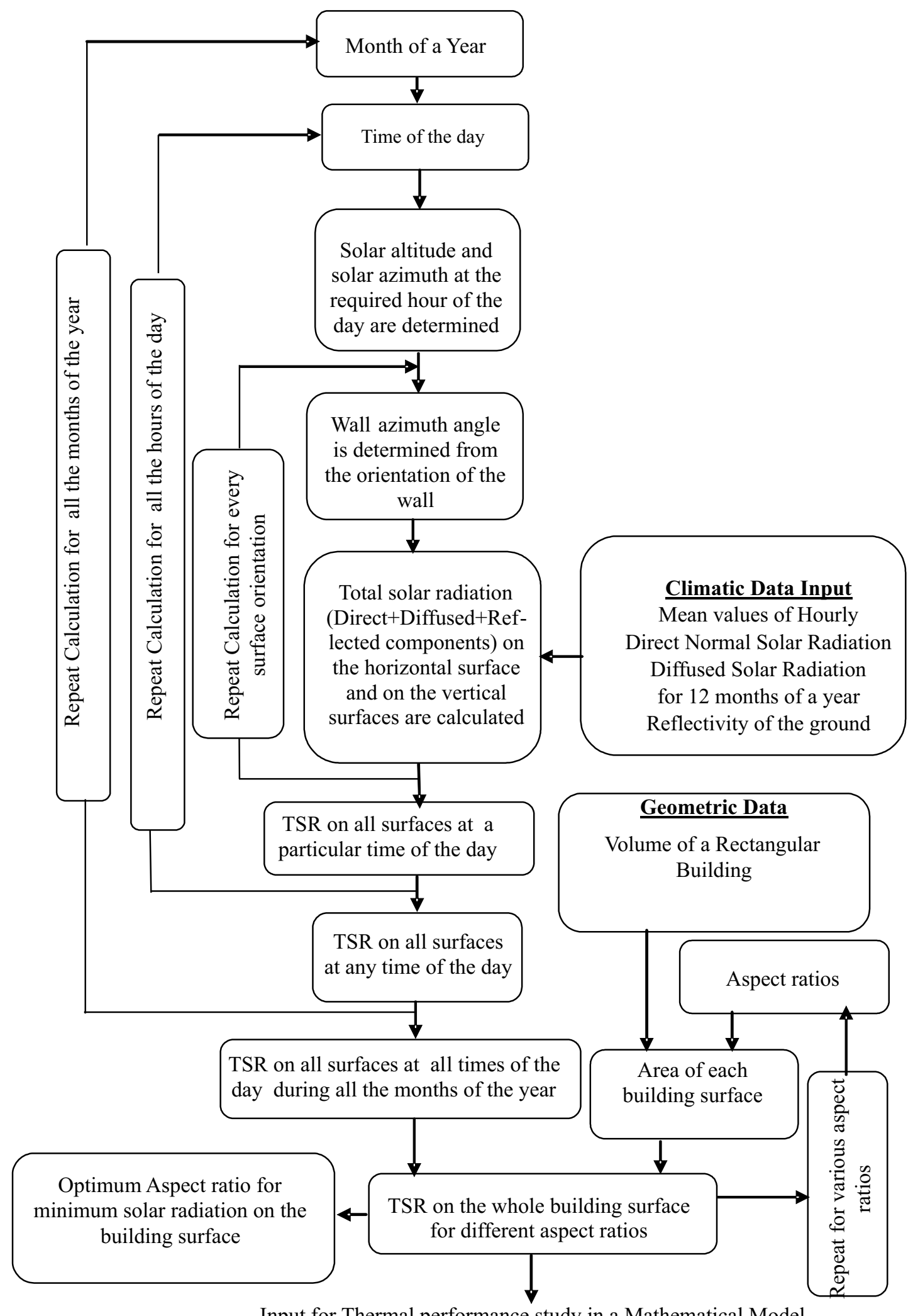

Input for Thermal performance study in a Mathematical Model

Fig. 6. Methodology for calculating total Solar Rediation on the building surface 


\section{RESULTS AND DISCUSSIONS}

The total solar radiation on any surface is the sum of the direct, diffused and reflected components of the solar radiation. The total solar radiation on the different surfaces of the building envelope in Chennai, India is computed from the weather data obtained from the handbook by Mani, 1981. The handbook provides mean hourly values of solar radiation, ambient air temperature, and relative humidity and wind speed based on data of 21 years. The variation of solar radiation on various walls and roof closely matches with the general trend shown in the Figure 7.

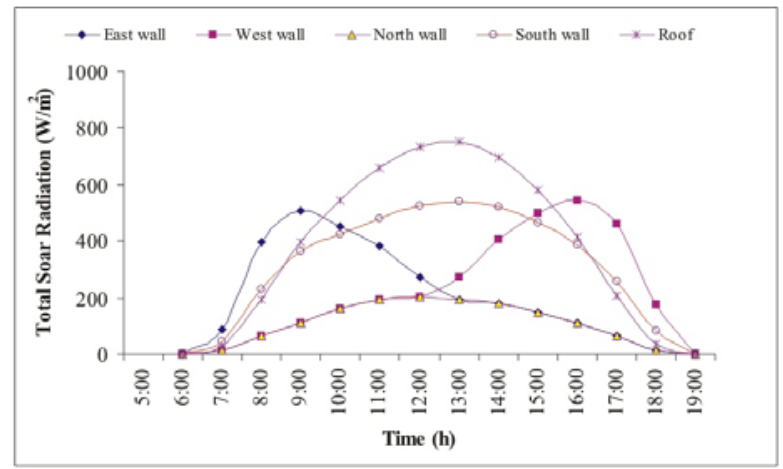

Fig. 7. Total Solar Radiation (TSR) Received By Different Building Surfaces in January

The maximum, mean, minimum values of daily average total solar radiation on building surfaces of different orientation in Chennai are shown in Figure 8. The thermal performance parameters for various wall forms are obtained from their thermo-physical properties, solar radiation and temperature profiles.

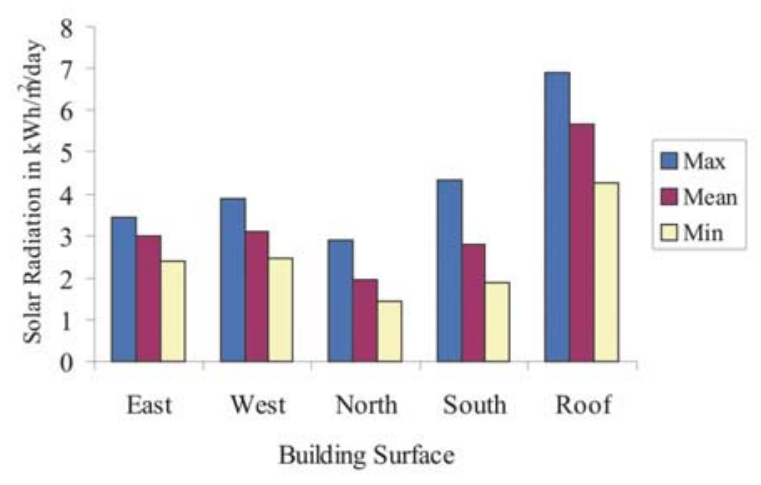

Fig. 8. Daily Maximum, Mean and Minimum Total Solar Radiation on Each Building Surface

\section{A. U- Values of Wall Forms}

The overall heat transfer coefficient $(U)$ indicates the heat flow rate per unit area per unit temperature difference under steady state conditions. It is preferable to have low U-values in hot climates, because it can substantially bring down the heat gain and hence the cooling loads. The thermal capacity (which is a product of density and specific heat) of a building component represents its ability to store heat energy before reaching steady state condition. The thermal diffusivity is the ratio of thermal conductivity to thermal capacity. The thermal capacity and thermal diffusivity of the building material determines the time lag, decrement factor and magnitude of heat loss. The multi-layer cavity walls and insulated walls have better ability to reduce inner surface temperature fluctuations due to lower U-value, lower decrement factor and higher time delay.

A brick wall of $220 \mathrm{~mm}$ thickness has $U$ value of 2.334 $\mathrm{W} / \mathrm{m} 2 . \mathrm{K}$. The $\mathrm{U}$ value decreases to $2.165 \mathrm{~W} / \mathrm{m} 2 . \mathrm{K}$, when $12.5 \mathrm{~mm}$ cement plaster is added on both sides. The addition of 50mm EPS (Expanded Polystyrene) insulation further decreases the $U$ value to $0.529 \mathrm{~W} / \mathrm{m} 2 . \mathrm{K}$. It is observed that the location of the insulation layer does not influence the $U$ value of the wall. The $U$ value of cavity wall is considerably lower than that of the solid brick wall, as it contains cavity filled with trapped air which is a good heat insulator. The addition of cement plaster on both sides of the cavity wall decreases the $U$ value by $7 \%$. The further addition of $50 \mathrm{~mm}$ insulation on outer or inner surface of cavity wall can reduce the $U$ value considerably. Instead of adding insulation on both sides of the cavity wall, it may be filled up in the cavity; but it has relatively higher $U$ value.

\section{B. U-Values of Roof Forms}

The value of overall heat transfer coefficient for the $\mathrm{RCC}$ roof of $100 \mathrm{~mm}$ is found to be $4.545 \mathrm{~W} / \mathrm{m} 2 . \mathrm{K}$, which is considerably higher than the suggested value of 2.33 W/m2.K (BIS 1995). The roof with a filler slab has about $21 \%$ less $U$ value and it can be attributed to the lower thermal conductivity of the brick tile used as filler slab. Addition of lime concrete in the roof slab decreases the Uvalue to $2.798 \mathrm{~W} / \mathrm{m} 2 . \mathrm{K}$. The $\mathrm{U}$ value of the RCC roof sample with $50 \mathrm{~mm}$ outer brick tiles, $100 \mathrm{~mm}$ lime concrete and inner plaster results in further reduction in $U$ value. The $U$ value of the roof from decreases with increase in roof layers, because of increased thermal resistance. When $50 \mathrm{~mm}$ insulation is added, the $U$ value of the roof forms drastically decreases (by $77 \%$ ) due to its high thermal resistance.

\section{Thermal Time Lag of Wall and Roof Forms}

The thermal time lag is determined by the thermal heat storage capacity of the material. The $220 \mathrm{~mm}$ brick wall is found to have a time lag of $6 \mathrm{~h}$. The time lag is mainly influenced by the thermo-physical properties of the material and their relative location. It is marginally 
nfluenced by the other climatic conditions. The time lag is increased to $10.75 \mathrm{~h}$ when thermal insulation of $50 \mathrm{~mm}$ is added on the outer wall. But the time lag is found to be only $8.25 \mathrm{~h}$, if the same insulation is added on the inner surface of the brick wall. The cavity wall is found to have higher thermal time delay compared to the full brick wall. Addition of insulation to the cavity wall also results in higher thermal time delay depending on their relative location.

It could be explained from the heat storage mechanism of the building material. The insulation on the outside reduces the heat flow rate into the building material. Reduced heat flow into the mass results in longer time to fill up the thermal storage capacity of the mass. If the insulation is provided inside, the process of filling the thermal energy up to its storage capacity does not get affected significantly and hence the thermal time delay

\section{Thermal Performance Index}

The Thermal Performance Index (TPI) indicates the maximum inner surface temperature in excess of $30^{\circ} \mathrm{C}$. In a non-air-conditioned situation, if TPI is less than 75 , it is rated as good. If the TPI increases, the thermal comfort deteriorates and becomes extremely poor if it becomes more than 225 .

The western wall is mostly found to experience maximum inner surface temperature among the walls. The $220 \mathrm{~mm}$ brick wall has the TPI of 90 , which is more than that required for the good thermal performance. When the cement plaster is added on both sides of the solid brick wall, the TPI reduces to 78 and addition of 50 $\mathrm{mm}$ insulation results in TPI of 66 which is less than 75. The cavity brick wall forms have a TPI less than 75 and the TPI becomes less than 50 when it is provided with 50 $\mathrm{mm}$ EPS insulation on its outer surface. Thus, the position of insulation also influences the TPI, with insulation closer to the outer wall exhibiting reduced TPI.

The TPI of the roof forms are very high compared to that of the wall forms. It is mainly because of the continued exposure of the roof to the solar heat for a long time and due to the fact that heavy roofs are not generally preferred to avoid excessive structural weights. The TPI of $100 \mathrm{~mm} \mathrm{RCC}$ roof is observed to be 285 , which is much higher than the desirable value of 50 or less.

The TPI of the building made of different combinations of walls and roofs are evaluated from the inner surface temperature distribution by area weighted average method. The TPI of a building with optimum aspect ratios is found to be less than 75 , if it uses the walls made of $200 \mathrm{~mm}$ brick plus plastering on both sides with insulated roofs. In the buildings with uninsulated roofs, the weighted average of TPI is found to be as high as 89 , indicating the poor performance of the building envelope. If the insulated roofs are used, the TPI reduces to the range of 32 (with the cavity wall form) to 43 .

\section{CONCLUSION}

The walls and roof of any building thermally interacts with the surrounding throughout a day due to change in environmental temperature and solar radiation. The walls and roof may be built as single layered or multi-layered forms so as to have suitable thermal storage capacity and diffusivity to obtain appropriate thermal time delay and decrement factor. The knowledge of thermal behaviour of building wall forms will enable the designer to select appropriate wall forms for different building surfaces to suit the functional requirements of a building interior space. A wall form with high heat storage capacity may be preferred for those spaces used for long periods of time, while a wall form with low heat storage itself would be sufficient for spaces which are to be used for short period during specific interval of time in a day.

Multi-layered wall forms, obtained by combining different elements so as to get effective heat storage capacity and diffusivity, can be the best option for the buildings (like residential houses) which are used for the whole day. Buildings that are used for short period of time in a specific part of the day (say forenoon or afternoon) may be designed with single layered wall forms. In stead of the conventional practice of using same materials for all wall surfaces of the building, the various surfaces of the buildings may be provided with different material layers and thickness so as to have required thermal time delay and decrement factor depending on their orientation and incident solar radiation to ensure better indoor conditions. The roof area is relatively less compared to wall area, but heat gain through the roof is high due to its prolonged exposure to the solar heat. The unwanted heat gain through roof can be easily reduced by using suitable insulation materials. The results of this study would be useful for improved passive solar design of the buildings for effective functional use of buildings. 


\section{REFERENCES}

[1] Asan H. and Sancaktar Y.S. 1998, 'Effects of wall's thermo-physical properties on time lag and decrement factor', Energy and Buildings, Vol.28, pp.159-166.

[2] BIS, 1978, 'IS:3792 : Indian Standard Guide for Heat Insulation of Non-Industrial Buildings', Indian Standards Institution, New Delhi.

[3] BIS, 1995, 'Handbook on functional requirements of buildings', Parts 1-4, SP 41 (S\&T) - 1987, Bureau of Indian Standards, Manak Bhavan, 9 Bahadur Sha Zhfar Marg, New Delhi, India.

[4] Humpherys M. 1978, 'Outdoor temperature and comfort indoors', Building Research and Practice, Vol.6, pp. 92-105.

5] Koenigsberger O.H., Ingersoll T.G., Mayhew A. and Szokolay S.V. 2000, 'Manual of tropical housing and building', Orient Longman, Chennai.

[6] Krishnan A., Baker N., Yannas S. and Szokolay S.V. 2001, 'Climate Responsive Architecture - A Design Hand Book for Energy Efficient Buildings', Tata McGrawHill Publishing Company Ltd, New Delhi.
[7] Mani A. 1981, 'Handbook of Solar Radiation Data for India', Allied Publishers, New Delhi.

[8] Mingfang T. 2002, Solar control for buildings, 'Building and Environment', Vol.37, pp.659-664.

[9] Nicole J.F and Humphreys M.A. 2002, 'Adaptive thermal comfort and sustainable thermal standards for buildings', Energy and Buildings, Vol.34, pp.563572.

[10] Threlkeld J.L. 1998, 'Thermal Environmental Engineering', Prentice-Hall, Englewood Cliffs, NJ.

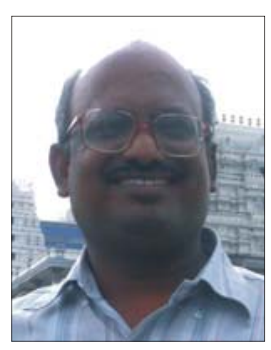

Dr.E. Natarajan is a Professor at the Institute for Energy studies, Anna University Chennai, and has over twenty years of teaching and research experience in the field of Energy Studies. He has guided four Doctoral students. He has visited USA, UK and Sweden to involve in energy related projects.

He has successfully conducted many International programmes and Conferences for the dissemination of recent developments in the area of energy and its effective utilization. 